\title{
MANEJO DE TRAUMA FRONTAL. REVISIÓN DE LITERATURA Y REPORTE DE CASOS
}

\author{
Aleida Neira H. Odontóloga ${ }^{1 *}$ y Camilo A. Eslava J., Odontólogo, Cirujano Oral y Maxilofacial ${ }^{2}$ \\ ${ }^{1}$ Residente del programa de Cirugía oral y Maxilofacial. Universidad Militar Nueva Granada. Bogotá \\ Colombia. ${ }^{2}$ Jefe Servicio de Cirugía Oral y Maxilofacial, Hospital Militar Central. Bogotá D.C Colombia.
}

\begin{abstract}
Resumen
Desde la época de Reidel (1898) han sido considerables los avances en el manejo del trauma frontal; sin embargo, el tratamiento para este trauma sigue siendo controvertido y si por alguna circunstancia el manejo no es el adecuado, se pueden presentar serias complicaciones. En este articulo se reportan siete casos manejados por el servicio de Cirugía Oral y Maxilofacial del Hospital Militar Central (HMC) de Bogotá, Colombia, y se hace una revisión de la literatura sobre manejo de fracturas de seno frontal y las diferentes técnicas utilizadas, especialmente en la obliteración del receso frontal con los materiales autógenos o aloplásticos disponibles y las complicaciones más frecuentes.
\end{abstract}

Palabras clave: receso frontal, cranealización, desfuncionalización, obliteración, mucocele

\section{MANAGEMENT OF FRONTAL TRAUMA. REVIEW LITERATURE AND REPORT OF CASES}

\begin{abstract}
Since the work of Reidel (1898), there have been considerable advances in the management of frontal trauma. However, the treatment for this trauma is still controversial, so if given the case of inappropriate management, it can imply serious complications. In this article seven cases handled by the service of Oral Surgery and Maxilofacial of the Central Military Hospital (HMC) of Bogotá-Colombia are reported. A literature review was prepared on managing fracture of frontal sinus and the different technologies used, especially in the frontal recess obliteration with available autogenous or alloplastic materials and the most frequent complications.
\end{abstract}

Key words: frontal recess, cranialization, defunctionalization, obliteration, mucocele

\section{ABORDAGEM DE TRAUMA FRONTAL. REVISÃO DA LITERATURA E RELATO DE CASOS}

\section{Resumo}

Desde o tempo de Reidel (1898) tem havido avanços consideráveis na abordagem de trauma frontal; porem, o tratamento para o trauma ainda é controverso e se por algum motivo, a abordagem não é adequada, complicações graves podem ocorrer. Neste trabalho nós relatamos sete casos tratados pelo Serviço de Cirurgia Bucomaxilofacial do Hospital Militar Central (HMC) de Bogotá, Colômbia, e uma

* Correspondencia: Aleida Neira alenei96@yahoo.es. Dirección postal: Servicio de Cirugía oral y maxilofacial, Hospital Militar Central, Tr. 3 No 49-00, Bogotá, Colombia.

Recibido: Mayo 18 de 2010 Aceptado: Diciembre 1 de 2010 
revisão da literatura sobre abordagem de fraturas do seio frontal e as diferentes técnicas utilizadas, especialmente na obliteração do recesso frontal com materiais autógenos ou aloplásticos disponíveis $e$ as complicações mais freqüentes.

Palavras-chave: recesso frontal, cranialização, desfuncionalização, obliteração, mucocele

\section{Introducción}

Las fracturas frontales corresponden a un $5-12 \%$ de las fracturas faciales, se asocian en un $32 \%$ con fracturas panfaciales, el $15 \%$ a fracturas de complejo NOE, el $17 \%$ con fracturas cigomáticas y un $35 \%$ con fracturas de orbita $(1,2)$. El trauma frontal es ocasionado por impactos de alta energía especialmente accidentes de tránsito, heridas por arma de fuego, caídas, deportes y asaltos (2). La pared anterior del seno frontal puede soportar de 800 hasta 2200 libras de fuerza $(3,4,5)$ pero al fracturarse, esta se puede propagar a lo largo de la órbita y complejo naso-orbito-etmoidal (3). En el $72,5 \%$ de los casos se presenta la fractura asilada de pared anterior, en el $25,5 \%$ la fractura de pared anterior y posterior, en el $25-50 \%$ con compromiso del receso frontal $(1,2)$, con fistula de LCR del $13 \%$ al $33 \%$ de las fracturas frontales (4).

\section{Anatomía y embriología}

El seno frontal es el último seno en formarse, es asimétrico y está dividido por el septum intersinusal, del 2 al $20 \%$ es hipoplásico (2), en el $10 \%$ es unilateral, en el $5 \%$ es una estructura rudimentaria y en el $4 \%$ está ausente. Inicia su desarrollo a los dos años a partir de la celdilla etmoidal o invaginación del hueso frontal a través del meato superior o del receso frontal $(3,5)$, su desarrollo se completa a los cinco años, radiológicamente es observable a los 5-7 años y la formación completa es entre los 10-12 años (2,3,6).Dentro de las láminas del hueso frontal se ubica el seno frontal con una pared anterior gruesa, una pared posterior profunda delgada que se relaciona con las meninges del lóbulo frontal, una pared medial delgada que lo separa del seno contralateral, un vértice arriba y medial, una base cuya parte lateral corresponde a la órbita y la parte medial se apoya sobre el etmoides elevada por las células de este hueso $(3,7)$.

El seno del hueso frontal, separado entre si por el tabique intersinusal, se comunica con el meato medio nasal a través del conducto nasofrontal con forma triangular (8), mide en promedio $28-32 \mathrm{~mm}$ de altura, 25-27 $\mathrm{mm}$ de ancho, con una profundidad de 1,5 a $2 \mathrm{~mm}(8,9)$, con capacidad aproximada de $5 \mathrm{ml}$ (3). El conducto nasofrontal (CNF) se ubica en posición posteromedial del seno frontal y desciende oblicuamente hacia abajo, adentro y atrás, hasta el meato medio, donde desemboca, su longitud suele ser de 15 a $20 \mathrm{~mm}$, y su diámetro de 2 a $4 \mathrm{~mm}(7,9)$, el piso del seno forma el techo de la órbita excepto en la pared medial que cubre el seno etmoidal (8). La mayoría de la literatura se refiere a la vía de drenaje como CNF, considerándose anatómicamente correcto como receso frontal, ya que no es una estructura tubular y es la comunicación entre el seno frontal y seno etmoidal; el tracto de salida del seno frontal incluye regiones críticas relacionadas con la permeabilidad de una comunicación nasofrontal $(10,11)$.

El conducto nasofrontal es un complejo formado por tres estructuras anatómicas distintas (infundíbulo, orificio y receso frontal) que constituyen el tracto de drenaje del seno frontal; tiene forma de reloj de arena cuya parte superior es el infundíbulo frontal ubicado en el piso del seno frontal, donde se estrecha con una inclinación medial y postero-inferior; luego está el orificio frontal u ostium en dirección al etmoides, es la parte más estrecha del tracto (2-4 mm de diámetro) y en la parte más inferior se observa el receso frontal, con forma de embudo invertido. Medialmente el receso limita con la lámina vertical del cornete medio, lateralmente con la lámina papirácea en su porción superior; en la parte posterior, la bulla etmoidal con la arteria etmoidal anterior y en la zona anteroinferior encontramos la eminencia nasal, la celda de Agger nasi, proceso unciforme o las celdillas frontoetmoidales. El calibre del receso frontal depende en gran medida de la neumatización de estas celdillas, siendo más estrecho cuanto más neumatizada se encuentre esta área (5,10-12). La mucosa del seno colinda con las células etmoidales y el receso frontonasal y se invagina en los agujeros de Breschet (drenaje venoso y ruta de diseminación de infecciones Intracraneales, conformado por epitelio cilíndrico ciliado. Los cilios son bañados por una solución protéica o moco producido por las células caliciformes intercaladas ciliadas de la 
mucosa del seno frontal, y a través del movimiento de los cilios lo mueve hacia el receso y es expulsado por el hiato semilunar al canal nasal (13).

\section{Clasificaciones de fracturas frontales}

El trauma frontal es el resultado de un gran impacto ocasionados por accidentes de tránsito, accidentes laborales o por armas de fuego. Aunque la clasificación de este trauma no es universal, en la literatura se han reportado varias, elaboradas por diferentes investigadores con el objetivo de ayudar al clínico a la planeación quirúrgica. Las diferentes clasificaciones coinciden en la localización anatómica y la observación intraoperatoria; para ayudar a simplificarlas se han tomado en cuenta tres aspectos: la fractura de pared posterior la cual es muy raro que se presente, la fractura de tabla anterior y posterior que conduce a lesión del receso frontonasal, la participación de pared medial de orbita y la fractura NOE que conduce a lesión del receso $(2,3,13,14)$.

Dentro de las clasificaciones reportadas están la de Stanley, 1989, que fue modificada por Gonty en 1999 y la clasificación de Freihofer y Donald. La de Stanley modificada por Gonty en el año 1999, facilita la descripción del patrón de fractura, incluye el patrón de fractura frontal y NOE, predice la lesión y posibles lesiones en el futuro. Establece cuatro tipos: Tipo I: fractura de tabla anterior con o sin compromiso de reborde supraorbitario y NOE, Tipo II: fractura de tabla anterior y posterior lineal o conminuta, Tipo III: fractura de tabla posterior y Tipo IV: a través del seno (15). La clasificación de Donald establece también cuatro tipos: Tipo 1. Pared anterior: A. Linear, B. Deprimida, C. Compuesta y D. Conminuta. Tipo 2. Pared posterior: A. Linear, B. Deprimida, C. Deprimida con fístula de LCR y D. Conminuta. Tipo 3. Receso frontonasal y Tipo 4 Fractura completa con pared anterior y posterior (16).

\section{Manifestaciones clínicas}

Al realizar el examen clínico es importante observar las heridas o laceraciones frontales y las depresiones que afectan la estética (una vez hay resolución de edema); es prioritario descartar alguna lesión asociada de urgencia vital. Se debe realizar examen oftalmológico y determinar lesiones oculares (8), parestesias a nivel supraorbitario, examen nasal si hay secreción de LCR (rinorrea), ya que es un signo importante para descartar, compromiso de tabla posterior y lesión de la duramadre $(1,6,8,13)$ y si es necesario, se realiza la prueba de glucosa (1).

\section{Apoyo diagnóstico}

Las radiografías convencionales son un apoyo importante especialmente la proyección de Caldwel y lateral, para evidenciar niveles hidroaéreos, opacidad del seno frontal o neumoencéfalo y la radiografía frontal con proyección 1:1 ayuda a la planeación con una proyección de la ubicación y forma anatómica del seno frontal (13). La tomografía computarizada (TC) con cortes axiales, coronales y sagitales nos ayuda a lograr una buena delineación de la fractura, es definitiva como complemento al examen clínico para determinar el patrón de fractura (8).

\section{Manejo de fracturas}

El manejo de fracturas frontales no es considerado una emergencia excepto si hay una de fuga de LCR, hematomas subdurales y epidurales; en esos casos es una urgencia de neurocirugía. Primero se debe estabilizar el paciente $(\mathrm{ABCDE})$ y la prioridad en el tratamiento es el manejo de forma multidisciplinar (Cirugía Maxilofacial, Neurocirugía, Otorrinolaringología (ORL) y Oftalmología) $(17,18)$.

Los algoritmos varían y dependen de un diagnóstico preciso, exploración física adecuada, tomografía computarizada, participación del receso frontal, compromiso o no de la pared posterior (1). El manejo depende de la patogénesis de la lesión, el tratamiento es guiado por los principios básicos de una adecuada movilización de la fractura, su reducción y fijación (1). El objetivo del tratamiento es restaurar la función, prevenir complicaciones tempranas y tardías, protección de estructuras craneales y obtener un buen resultado estético, el cual es considerado un objetivo secundario $(8,9,13,19-21)$.

Stanley en el año 1989 se planteó las siguientes preguntas: si la fractura no se trata, ¿dará lugar a complicaciones inmediatas o diferidas? y en los casos que se requiera una cirugía ¿̇cuál es el procedimiento quirúrgico adecuado? A pesar que han pasado más de 20 años, aún no hay una respuesta definitiva $(14,15)$. No hay una regla universal que indique cual es la intervención quirúrgica más adecuada para lograr los objetivos óptimos y hasta la mejor modalidad del 
tratamiento es controversial $(15,20)$. Debido a que el tratamiento debe ser individualizado y no reducido a un algoritmo universal, se considera un desafío para el cirujano ejecutar el procedimiento más apropiado $(9,19,22)$.

Los puntos a tener en cuenta para la selección del tratamiento depende del patrón de fractura, el alcance de la lesión, la participación del receso frontal el cual es evaluado intraoperatoriamente y la pérdida de integridad de la duramadre. La escogencia del procedimiento a seguir es fundamental y el cirujano debe ser capaz de hacer los cambios necesarios en el momento de la cirugía, cuando visualiza que el plan de tratamiento planificado no es el más adecuado, y de esta forma se asegura una reducción de las complicaciones y del número de secuelas a largo plazo $(15,22,23)$.

Una vez se tenga un buen examen clínico y tomográfico, se clasifica la fractura y se procede a planificar el tratamiento. Hay diferentes formas de abordar la lesión, están el abordaje coronal que es el más usado, en $\mathrm{H}$ o a cielo abierto (sobre el puente nasal), alas de gaviota (dos incisiones curvas debajo de la frente terminando en la raíz nasal), mariposa (mezcla de cielo abierto y alas de gaviota), abordaje de Linch (laterales) y por las laceraciones presentes $(2,6,9)$.

\section{Fractura de tabla anterior sin desplazamiento}

Es una fractura lineal o con mínimo desplazamiento (uno o dos $\mathrm{mm}$ ), es una fractura no quirúrgica que no afecta la estética; el tratamiento es observación, se debe mantener un seno funcional y se debe recomendar no sonarse, ni estornudar, evitar la tos, no levantar objetos pesados y no hacer ejercicios fuertes (figura 1) $(1,4,8,14,19,24)$.

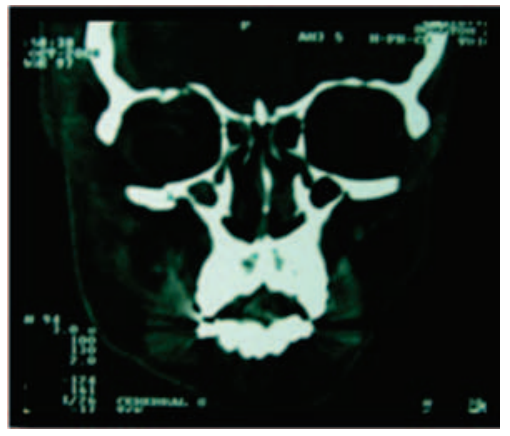

Figura 1. Tomografía con corte coronal. Fractura de tabla anterior derecha sin desplazamiento del fragmento óseo.
Fractura de tabla anterior desplazada

Es una fractura desplazada igual o mayor al grosor de la tabla y se observan deformidades de contorno afectando la estética; el tratamiento para este tipo de fracturas es quirúrgico (8). Si al evaluar el estado del receso frontal no se observa lesión, se procede a la reparación del seno manteniendo la preservación de la anatomía incluyendo el ducto, la mucosa tabla anterior y posterior, con reducción anatómica y estabilización de la fractura utilizando placas de titanio de bajo perfil o placas reabsorbibles en máximo diez días, una vez haya resolución de edema que enmascara la lesión (figura 2) $(1,2,4,5,14,19)$. Si hay compromiso NOE o reborde orbitario superior, se verifica el estado del receso frontal; si está lesionado se desfuncionaliza y se oblitera con hueso autólogo y grasa abdominal $(15,19)$.

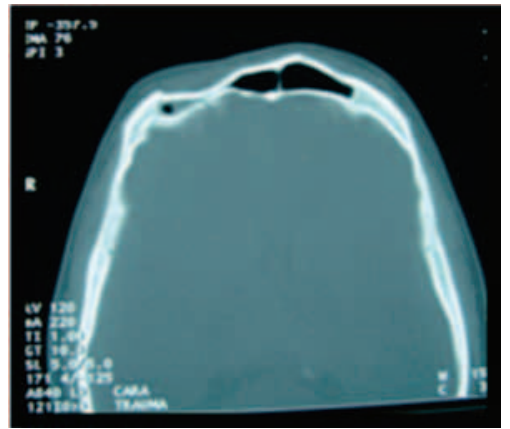

Figura 2. Tomografia computarizada con corte axial. Se observa fractura de tabla anterior derecha con desplazamiento hacia el interior del seno frontal.

\section{Fractura con compromiso de tabla posterior}

En este tipo de fractura se debe evaluar el estado de la duramadre si está intacto, si no hay presencia de fistula de LCR, si no hay daño neurológico y si no hay compromiso del receso frontal. La conducta a seguir es observación, control radiográfico y tomografía a las seis semanas. Si se observa un seno radiopaco se puede considerar drenaje endoscópico transnasal; la fractura de pared anterior se procede con los mismos objetivos descritos en fracturas desplazadas de tabla anterior $(1,4,8)$; si hay lesión del receso frontal se desfuncionaliza y se aisla el seno de la cavidad nasal obliterando el receso frontal (figura 3) $(4,5,14)$. 


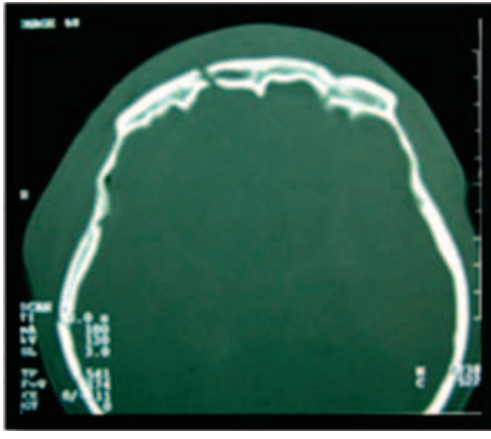

Figura 3. Fractura de tabla anterior sin desplazamiento y factura de tabla posterior con desplazamiento mínimo.

\section{Fractura con compromiso de tabla posterior desplazadas}

Es una fractura con conminuciones o muy desplazada; el desplazamiento se mide con el grosor de la tabla, el cual es igual o mayor en éste tipo de fracturas, con compromiso de la duramadre y comunicación del contenido intracraneal con la mucosa sinusal (8). En el manejo se conservan todos los principios de desfuncionalización del seno, retirando toda la mucosa, obliteración el receso frontal con grasa autóloga y/o hueso autólogo; la cranealización (se hace en colaboración de neurocirujanos) expandiéndose el lóbulo frontal al espacio ocupado por el seno frontal y aislando el contenido intracraneal con colgajo pericraneal o gálea frontal. Si hay fistula del LCR mayor a cuatro días se recomienda el drenaje espinal con tratamiento antibiótico, procedimiento que ha sido exitoso en un $50 \%$ de los casos. Si esta continua por más de diez días se realiza cranealización y desfuncionalización $(1,3,4,5,8,14,22,23,25,26$,$) .$

La reparación de la duramadre con parche fascial, colgajo pericraneal vascularizado que suministre sangre a los injertos y tejidos craneales (3). Si en las anteriores se compromete fractura NOE $\mathrm{u}$ otras fracturas de orbita, se reduce primero el seno frontal y posteriormente reducción de fractura NOE, pared medial y reborde orbitario superior (3). El tratamiento definitivo debe realizarse dentro de las 24 a 72 horas de la lesión a menos que otras lesiones importantes contraindiquen la atención quirúrgica; los antibióticos intravenosos son administrados antes de la cirugía y después del procedimiento (figura 4) (26).
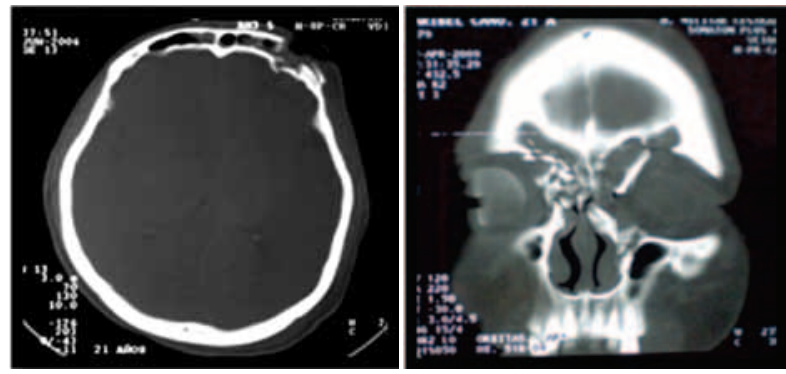

Figura 4. Tomografías con cortes axilares y coronales. Se observa la fractura de tabla anterior y posterior con considerables conminuciones y desplazamiento de fragmentos; en el corte coronal se observa la asociación a otras facturas como NOE.

\section{Examen del receso frontal}

Es importante evaluar si hay lesión o no del receso frontal verificando el drenaje al meato medio, y su permeabilidad intraoperatoriamente inyectando azul de metileno o fluoresceína $(10,20,26)$. Se puede utilizar stens para mantener la permeabilidad del receso frontal, los cuales están indicados en los casos de recesos con diámetro menor a cinco $\mathrm{mm}$; para ello se coloca un tubo de catéter o silicona hacia la fosa nasal por un tiempo de siete a veintiún días, con el fin de facilitar la epitelialización del conducto y la formación de la mucosa en la etapa de cicatrización entre más tiempo se favorece la recanalización del conducto $(1,13,20,27)$.

El mecanismo de la obliteración es la estimulación de la osteogénesis y la fibrosis (28); para asegurar el los principios esenciales del éxito de la obliteración del receso incluye es importante eliminar meticulosamente la mucosa visible y la incluida en las invaginaciones vasculares en el hueso (exenteración de la mucosa) o espacios de Breschet y no dejar espacios muertos; también se debe eliminar el septum intersinusal con curetas e instrumentos rotatorios de alta velocidad. La oclusión del receso frontal debe ser permanente, aislando la comunicación con senos paranasale; así el seno frontal se trata como una cavidad aislada y se debe evitar la formación de mucoceles y mucopioceles (figura 5) $(1,3,14,15,23,24,26,29)$.
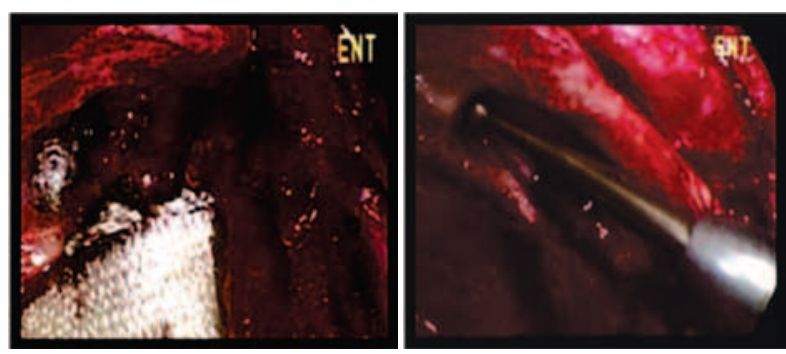

Figura 5. Se observa el receso frontal y eliminación de la mucosa con elementos rotatorios. 


\section{Materiales de obliteración}

Los principios de obliteración se basan en la desfuncionalización del seno con eliminación de la mucosa y oclusión permanente del receso. En la obliteración se puede utilizar muestras autólogas o materiales aloplásticos (30).

\section{Materiales autólogos}

\section{Grasa.}

Es el material preferido por los cirujanos, popularizada por Montgomery Goodale (31); es fácil de obtener, con mínima morbilidad, histológicamente tiene núcleos prominentes vasculares, crea una barrera entre cavidad nasal y neurocráneo e impide el flujo retrogrado de microbios, proporciona un colchón para la duramadre y es resistente a la infección. El grado de vascularización depende del lecho vascular, la tasa de reabsorción es lenta y es reemplazado por tejido fibroso gradualmente y a los 24 meses disminuye un $20 \%$ (figura 6) $(3,14,15,22,23)$.

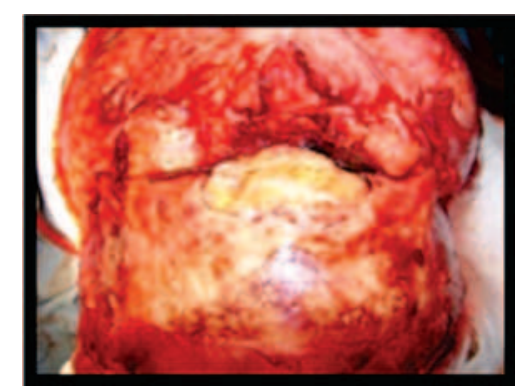

Figura 6. Colocación de grasa autóloga en cavidad sinusal.

\section{Hueso}

La cresta ilíaca y calota han sido los sitios donadores de hueso más utilizados (2); se ha demostrado en estudios realizados que se presenta menos reabsorción en el hueso membranoso que el endocondral debido al origen embriológico; el hueso membranoso tiene una corteza más dura y densa y mantiene mejor volumen; la zona esponjosa es más delgada en el hueso endocondral $(32,33)$. También se ha demostrado que al usar hueso pulverizado en pacientes jóvenes, este se transforma en tejido fibroso y es permeable a nuevos vasos; hay reosificación de la periferia y por osteogenesis en el centro del defecto, no requiere de paredes óseas intactas, contiene proteínas morfogenéticas óseas (mediador de osteoinducción) y a los 24 meses se observa radiopacidad (figura 7) $(2,10,14,32)$.

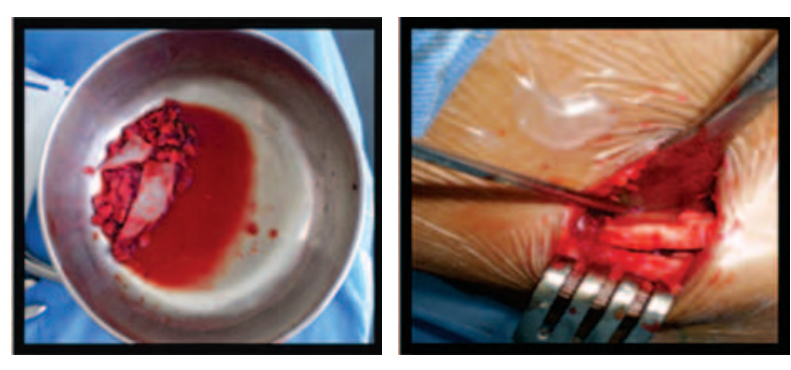

Figura 7. Hueso autólogo tomado de cresta ilíaca y preparación de chip para ser colocado en el receso frontal.

\section{Musculo Temporal}

Es injerto no vascularizado, sufre licuefacción, necrosis y sustitución por fibrosis, hay morbilidad de zona donante y depresión de la zona temporal y posteriormente trismos (14).

\section{Colgajo pericraneal}

Es vascularizado, aísla el contenido intracraneal, puede ser obtenido con facilidad y rapidéz y por encontrarse en el campo quirúrgico, evita la morbilidad de la zona donante. Suministra sangre a los tejidos calvarios e injertos vascularizado por la arteria supratroclear y supraorbitaria $(23,26)$; al realizar la disección a nivel subgaleal sin extenderse más de un cm craneal de la cresta supraorbitaria para no comprometer el suministro de sangre al colgajo, se debe tener presente la variación en la anatomía de la bifurcación de las ramas superficiales y profundas de las arterias supraorbitaria y supratroclear y el drenaje venoso a través de la vena supraorbitaria que corre un $\mathrm{cm}$ cefálico al reborde supaorbitario (34). Los resultados han sido importantes en la separación del contenido intracraneal y se asegura con pegamento de fibrina (figura 8) (25).

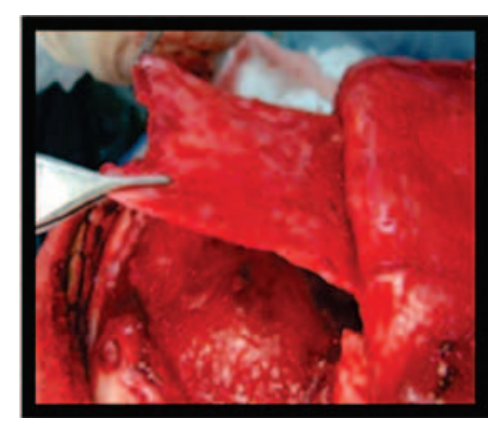

Figura 8. Abordaje coronal. Colgajo pericraneal previo a la colocación en la cavidad craneal, aislando el contenido intracraneal de la cavidad nasal en cranealización y desfuncionalización de seno frontal. 


\section{Gálea frontal}

Deja intacto el periostio en la zona de la fractura, se eleva del lado sano, ayuda a la cicatrización, es un buen aporte de vascularidad y es el pilar de la resistencia a la infección. La fibrina, un pegamento obtenido de trasplante autólogo y que parece que no interfiere con la cicatrización ósea, se usa para fijar el injerto al suelo del seno y le han atribuido propiedades osteoinductivas (figura 9) $(22,32)$.

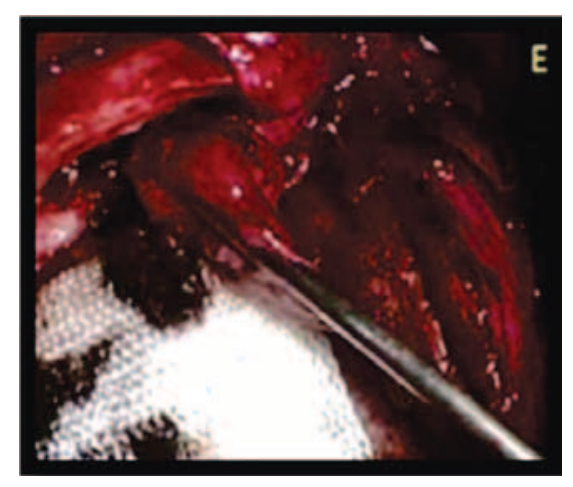

Figura 9. Colocación de colgajo frontal en zona de seno frontal aislando el contenido craneal a la cavidad nasal.

\section{Materiales aloplásticos}

\section{Ionómero de vidrio}

Es un híbrido con partículas de vidrio; es osteoconductor, no presenta exotermia, favorece la proliferación de tejido fibroconectivo en lugar de hueso nuevo y es sustituto de hueso. Los estudios de este material no superan los cinco años $(14,19)$.

\section{Cartílago liofilizado}

Actúa como un enrejado donde las células osteocomponentes proliferan, se observa gradualmente más denso a medida que el injerto de cartílago es sustituido por tejido óseo; la integración histológica completa con el tejido óseo ocurre al año. Este es un proceso gradual, la posibilidad de una infección secundaria es reducida al igual que la formación de mucocele. Los injertos de cartilago tienden progresivamente a la sustitución ósea, proceso que se inicia aproximadamente a los 25-50 días después de la implantación, y en un período de un año es sustituido por completo (35).

\section{Cemento de fosfato de calcio óseo}

Tiene propiedades osteoconductoras, es más soluble a pH bajo lo que facilita la resorción y sustitución ósea; su desventaja es ser propenso a degradación y crecimiento interno de la mucosa $(14,19)$. El fosfato tricálcico ß es osteoconductor, con estructura cristalina de alta porosidad la cual permite la penetración de las células osteoprogenitoras de la sangre y de productos sanguíneos del entorno; el diámetro de los poros es de $1-1000 \mathrm{~mm}(1 \mathrm{~mm})$. Sus propiedades aumentan cuando se combina con hueso autólogo, acelerando el proceso de osteoneogénesis (30).

Cemento óseo de hidroxiapatita (fosfato de calcio no cerámico)

Tiene propiedades osteoconductivas, se moldea fácilmente de acuerdo al defecto, es resistente al crecimiento de mucosa sinusal dentro del material y a la infección; el contacto con sangre, LCR y líquido paranasal hace que se disuelva completamente favoreciendo la formación de mucocele $(14,19)$.

\section{Metacrilato de metilo}

Es una resina acrilica y es de los materiales aloplásticos el más utilizado en cirugía de cabeza y cuello; produce reacción exotérmica cuando el monómero y el polímero se combinan, se pueden presentar reacciones del tejido a cuerpo extraño. (34).

\section{Osteogénesis espontánea.}

Cavidad con hueso sano y sangre, la pared posterior promueve la formación de hueso nuevo, pero el tiempo que se espera puede generar infecciones $(1,3,8,22)$.

\section{Manejo Endoscópico}

En los últimos diez años el manejo endoscópico ha sido exitoso y su utilización se reduce a fracturas simples no desplazada de tabla anterior que no incluya reborde orbitario superior $(13,21,36,38,39,40)$. Este método mínimamente invasivo, ofrece una alternativa para el tratamiento del seno frontal y permite una resección amplia del suelo del seno frontal para facilitar el drenaje. Los estudios realizados en donde se ha utilizado esta técnica han mostrado excelentes resultados fun- 
cionales, con buena permeabilidad residual del seno frontal $(26,40,41)$.

La técnica quirúrgica es similar al Brow lift; la "incisión de trabajo" de 3 a $5 \mathrm{~cm}$ parasagital, $3 \mathrm{~cm}$ por detrás de la línea del cabello y va a través del periostio al hueso, la "incisión endoscópica" de 1 a 2 cm subperióstico, se coloca a la misma altura a 4 a $6 \mathrm{~cm}$ medial a la incisión de trabajo, se utiliza un endoscopio con angulación de 30 grados y una incisión en la piel de la ceja para ayudar a la reducción de los fragmentos $(14,36,38)$; sin embargo, se ha encontrado que es necesario abordar los fragmentos a través de incisiones pequeñas en la frente, directamente sobre las fracturas, lo que permite la reducción anatómica de los segmentos de fractura de la pared anterior (36).

El abordaje endoscópico evita lesionar el nervio supratroclear y supraorbitario, porque si se lesiona puede ocasionar una disminución de la sensibilidad de la frente y cefaleas $(10,11)$. Con el método de endoscopia asistida, sólo dos pequeños incisiones son necesarias para alcanzar los mismos resultados que el abordaje bicoronal, proporciona una visualización directa y magnificada, evita lesión neurovascular, hay una mínima manipulación del tejido y desde el punto de vista de la estética el resultado es bueno, especialmente para los pacientes calvos y ayuda a evaluar fístulas de líquido cefalorraquídeo. Este método no es adecuado para todas las fracturas del seno frontal; las fracturas de pared anterior con conminución y las lesiones de mucosa pueden requerir una reducción abierta. Tampoco es aplicable en las fracturas desplazadas de pared posterior con daño en duramadre, asociadas a trauma en órbita y extensas fracturas de huesos del cráneo $(38,40,42)$.

\section{Complicaciones}

Las fracturas aisladas del hueso frontal con compromiso de pared anterior y posterior presentan un mayor riesgo de complicaciones como infeccioness (43). El manejo inadecuado del seno frontal, de la mucosa y del receso frontal llevará a complicaciones obstructivas y complicaciones patológicas (26). La participación de la pared posterior se asocia más comúnmente con daño a las estructuras posteriores del globo (neuropatía óptica traumática, parálisis del nervio motor ocular común y lesiones del quiasma óptico (18).

\section{Complicaciones tempranas}

El dolor en la zona de la frente, anestesia transitoria y diplopía duran aproximadamente de dos a tres semanas. Se pude presentar infección de heridas (3). En los primeros seis meses de la cirugía, la más común es la sinusitis frontal con síntomas de fiebre, cefalea, eritema en la frente, dolor de cabeza, dolor ocular, dolor nasal; el tratamiento inicial es con descongestionantes y antibióticos (26). Las fístulas de LCR pueden ocurrir después de un período muy impredecible del trauma, por pequeñas laceraciones que puedan afectar a la duramadre; el procedimiento a seguir es hacer un drenaje lumbar más tratamiento con antibióticos. Si persiste más de diez días se hace una reexploración y cranealización $(26,44)$.

\section{Complicaciones tardías}

Sinusitis producida por el moco de las glándulas del aparato respiratorio o por exposición a material aloplástico; su manejo es con antibiótico y descongestionantes $(1,45)$.

Trombosis del seno cavernoso el cual se propaga por los agujeros de Breschet, propagación de infección por espacios de Virchow desde la pared posterior a la duramadre, senos venosos, venas subdurales, venas cerebrales $(3,45)$.

Meningitis con cambios del estado mental, fiebre, rigidéz del cuello; su manejo se inicia con antibióticos de alto espectro $(1,3)$.

Osteomielitis es una infección alrededor del espacio medular o a través de las venas diploicas que no tienen válvulas; cuando se complica hay la formación de un absceso subperiostico y se produce el tumor de pott $(45,46)$.

Absceso cerebral o absceso subdural con pérdida de apetito, fatiga, letargo, cambios sutiles de personalidad (3).

Mucocele y Mucopiocele (figura 10). El mucocele se produce por la acumulación de moco en un sitio cerrado como por ejemplo el seno frontal, generándose una expansión. El tracto de salida del receso es como reloj de arena, cuando hay obstrucción del drenaje del tracto de salida éste, se deteriora y conduce a la 
formación de mucopioceles por la infección del mucocele. La formación de mucoceles es una complicación, que puede desarrollarse años después del trauma y los síntomas pueden pasar desapercibidos durante un largo periodo de tiempo; por lo tanto, se debe hacer un seguimiento por varios años con controles anuales, independientemente que el tratamiento haya sido quirúrgico o no quirúrgico $(1,50,52)$.

La colección de moco con ampliación y destrucción de limites óseos pueden presentarse años después del tratamiento inicial. Varios estudios han demostrado que el revestimiento del mucocele produce resorción ósea por las prostaglandinas y colagenasas de los fibroblastos que son estimulados por las citoquinas producidas por los linfocitos y monocitos. Los principales síntomas a nivel orbitario son dolor, edema, exoftalmos, diplopía y pérdida de la visión cuando se genera presión en la parte posterior del seno, meningitis, neumoencéfalo, absceso y convulsiones $(3,6,19,29,45,47-50)$. Se debe proceder a cranealización y desfuncionalización del seno frontal. Si el mucocele no es manejado, se puede generar un absceso cerebral, meningitis y empiema epidural, con invasión bacteriana por medio de la venas diplóicas que se conectan con la vascularidad de la mucosa del seno hacia el sistema venoso intracraneal.

Con el tiempo los mucoceles pueden producir síntomas de sinusitis crónica; en estos casos el tratamiento varía desde la cirugía endoscopia nasosinusal hasta la craneotomía y exposición del seno, con extirpación radical del mucocele y cranealizacion y obliteración del receso frontal el cual es el más aceptado por ser un tratamiento radical $(26,45,51)$. La razón más común para el fracaso sigue siendo el retiro incompleto de la membrana mucosa, ya sea en el receso frontal o mayoría de los aspectos laterales del seno frontal (49).

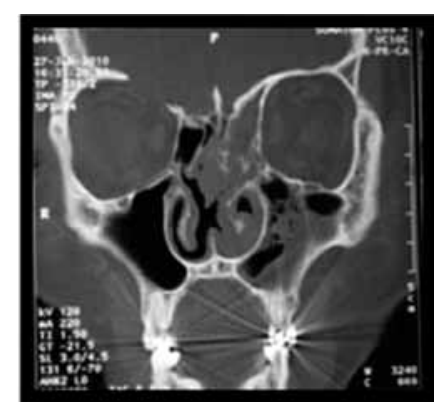

Figura 10. Mucocele recurrente en seno frontal izquierdo, posterior a un TCE de 12 años, previo tratamiento en seno derecho, se realiza cranealización y desfuncionalización de seno izquierdo. (Cortesia Dr Silva, Dra Cardozo Servicio de ORL HMC).
Complicaciones estéticas con defectos de contorno, desplazamiento inferior de la orbita por falta de corrección adecuada de la eminencia, entrecejo, cresta supraorbitaria, techo de orbita y proyección frontal o estabilización inadecuada de la factura. La contractura cicatrizal de la piel de la frente produce alteración del contorno, haciendo visible el material de osteosíntesis dado por la lesión de la piel o reducción del espesor del colgajo pericraneal o galea frontal. Para su tratamiento es necesaria la expansión tisular para obtener el tejido necesario para la reconstrucción. El desplazamiento hacia abajo del globo ocular es por la incapacidad de restaurar el contorno y proyección del hueso frontal en la órbita (figura 11) $(3,45)$.

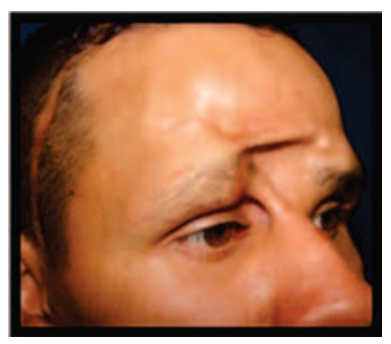

Figura 11. Contractura cicatrizal de la piel de la frente con alteración del contorno haciendo visible el material de osteosíntesis.

\section{Reporte de casos}

En el servicio de urgencias del HMC de Bogotá, Colombia, durante los años 2006 al 2009 se atendieron 4100 pacientes con trauma facial y craneal; de estos, 1211 corresponden a diferentes traumas faciales que presentaban lesiones que involucraban desde tejidos blandos hasta diferentes tipo de fracturas faciales. 32 casos $(2,64 \%)$ correspondían a trauma en la región frontal, que también variaban desde lesiones de tejidos blandos hasta fracturas frontales; de estos pacientes, $19(1,56 \%)$ presentaban fracturas frontales que fueron atendidos por el servicio de cirugía oral y maxilofacial. La gran mayoría de los pacientes eran del sexo masculino (31:1) y el promedio de edad era de 27 años.

Etiología: De los 32 pacientes que presentaban trauma en la región frontal, once fueron heridos por arma de fuego tipo fragmentación (34,3\%), siete heridos por arma de fuego alta velocidad $(21,8 \%)$, siete por golpes ocasionados al caerse $(21,8 \%)$, cuatro por accidentes de tránsito $(12,5 \%)$ y tres por trauma contuso $(9,3 \%)$.

De los 32 casos asociados a traumas frontales, siete $(21,8 \%)$ eran fracturas panfaciales, seis $(18,75 \%)$ 
fracturas NOE, cuatro $(12,5 \%)$ orbitozigomáticos y quince $(46,8 \%)$ fracturas aisladas reborde orbitario (incluyendo laceraciones de tejidos blandos). De los 19 casos de fracturas frontales, doce $(63,2 \%)$ presentaban fractura de pared anterior y siete $(36,8 \%)$ de pared anterior y posterior.

A continuación se presentan siete casos de pacientes con fracturas frontales y sus diferentes manejos de acuerdo la extensión de la lesión.

\section{Caso 1}

Paciente de 30 años con trauma facial por accidente de tránsito, remitido al Hospital Militar Central (HMC) de Bogotá al mes de evolución posterior al trauma. Al ingreso se observa depresión en zona frontal derecha, afectando estética (figuras 12A y B). En la tomografía se observa fractura frontal con pared anterior de seno frontal desplazada sin compromiso de receso frontonasal y reborde supraorbitario derecho (figuras 12C y D). Se realiza procedimiento quirúrgico a los 33 días del trauma con abordaje coronal, exposición de fracturas, reducción y fijación interna rígida con sistema 1,0 en pared anterior de seno frontal derecho y reborde supraorbitario (figuras $12 \mathrm{E}$ y F). En las figuras $12 \mathrm{G}$ y H se muestran las fotos posoperatorias del paciente con cicatriz en abordaje coronal y estética adecuada en región frontal. En las radiografías posoperatorias se observa el material de osteosíntesis en región frontal (figuras 12 I y J).

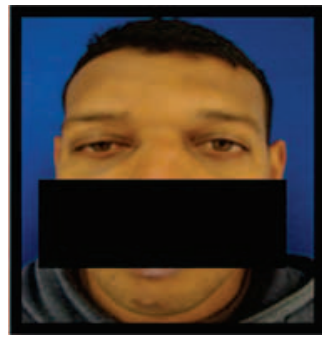

A

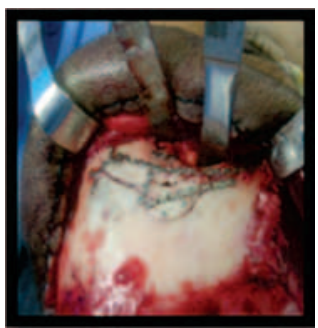

$\mathbf{F}$

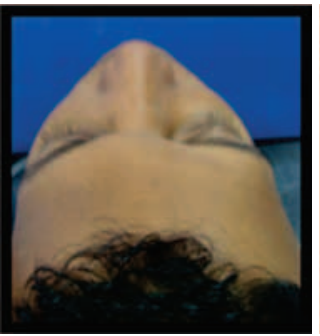

B

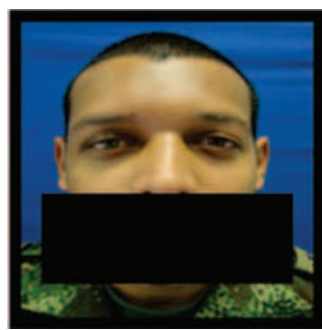

G

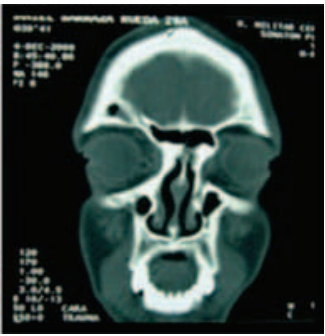

C

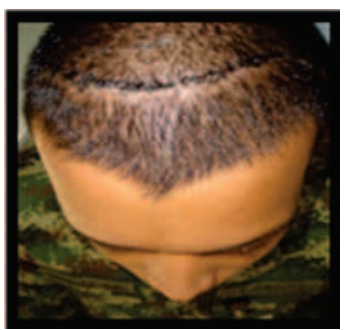

H

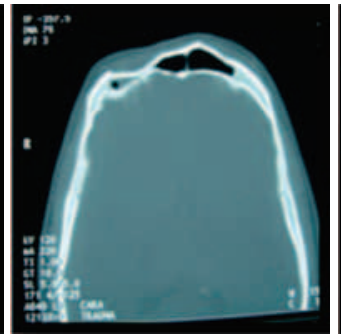

D

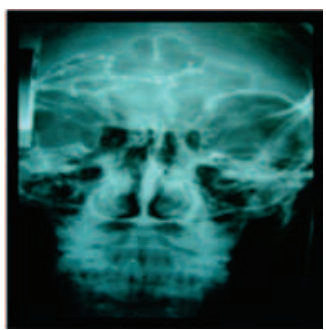

I

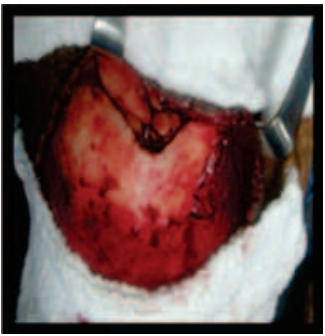

E

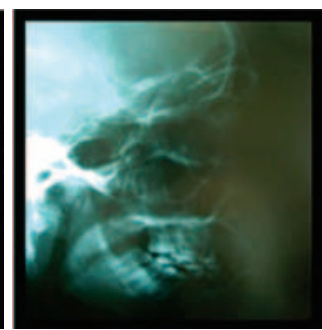

J

Figura 12. Paciente con trauma facial por accidente de tránsito

\section{Caso 2}

Paciente de 24 años, procedente de Villavicencio, remitido al HMC con un cuadro de tres días evolución con herida por arma de fragmentación. Al ingreso se observa herida en región frontal derecha y esquirlas en región facial (figura 13A). En las figuras 13B, C y $D$ se muestran tomografías donde se observan fractura conminuta pared anterior de seno frontal derecho sin compromiso de conducto nasofrontal y fractura techo de orbita derecha. Se realiza procedimiento quirúrgico a los dos días de su ingreso con abordaje por el sitio de la herida, verificación del estado de seno, exposición de fragmento óseo y reducción de la fractura de pared anterior de seno frontal derecho con sistema 1.0 (figuras 13E, F y G). En las figuras $13 \mathrm{H}$ e I se muestran fotografías posoperatorias del paciente en donde se puede observar estética favorable y en la figura 13J una radiografía donde se observa el material de osteosíntesis. 


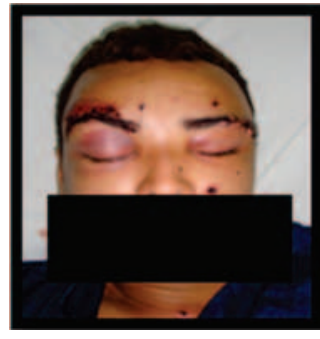

A

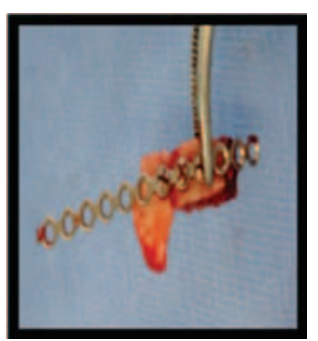

$\mathbf{F}$

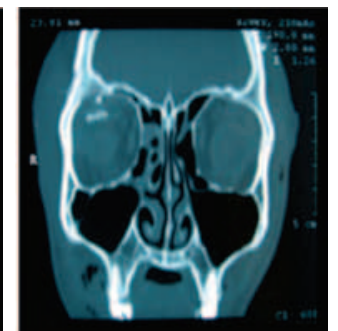

B

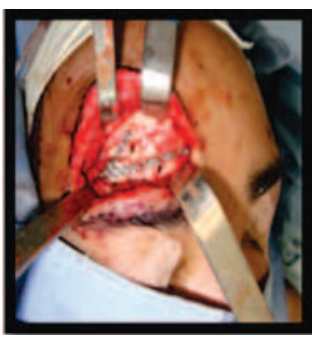

G

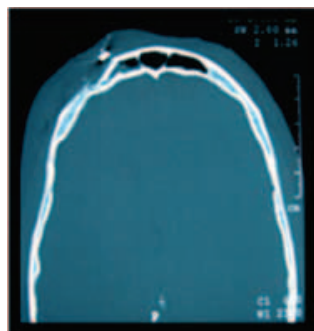

C

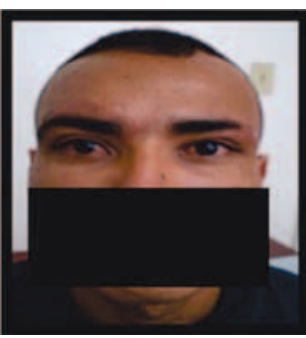

H

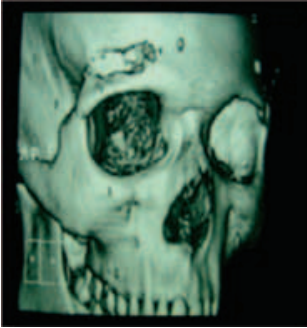

D

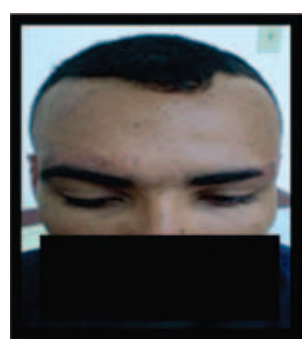

I

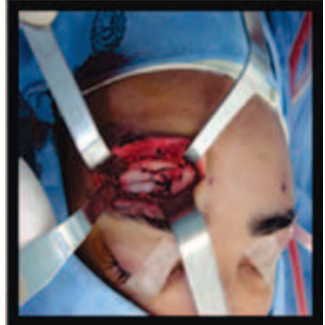

E

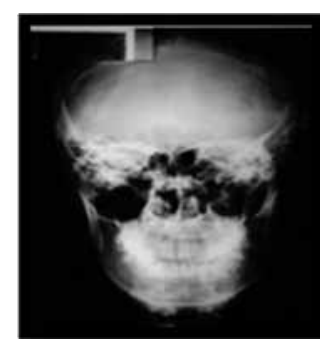

J

Figura 13. Paciente con herida por arma de fragmentación

\section{Caso 3}

Paciente de 21 años procedente de Mocoa, con un cuadro de 16 horas de evolución por accidente de tránsito. El manejo inicial se hizo en el Hospital de Mocoa y una vez se estabilizó fue trasladado al HMC para continuar con el manejo y tratamiento; como antecedente importante, el paciente presentaba una secuela de trauma a nivel frontal por accidente de tránsito ocurrido hace cuatro años. En la figura 14A se muestra al paciente antes de la cirugía; en el examen inicial se palpa depresión en región frontal, escalón en pilar fronto malar derecho, crepitación en pirámide nasal, rebordes infraorbitarios no valorables por edema, reflejos pupilar y consensual positivos, quemosis OD y edema y equimosis bipalpebral bilateral. Escalón en basal mandíbula a nivel se sínfisis y para sínfisis dere- cha. En las figuras 14B, C y D se observan las tomografías que muestran fractura de la pared anterior de seno frontal desplazada (secuela de trauma), fractura malar tipo IV bilateral, fractura de huesos nasales, fractura para sagital de paladar, fractura en sínfisis mandibular y trauma dentoalveolar del 11. El paciente ingresa a la UCI y se realiza procedimiento quirúrgico a los dos días de su ingreso, con abordaje coronal (figura 14E), defecto de pared anterior de seno frontal deprimida consolidada del antecedente de trauma (figura 14F), colocación de malla de titanio de sistema 1.0 para restaurar el contorno (figura 14G) y reducción abierta de fracturas panfaciales (figura $14 \mathrm{H}$ ). En la figura 14I se muestra una fotografía del paciente y en las figuras $14 \mathrm{~J}$ y $\mathrm{K}$ se muestran radiografías donde se observa el material de osteosíntesis en la región facial, las cuales fueron tomadas a los dos meses de la cirugía. 


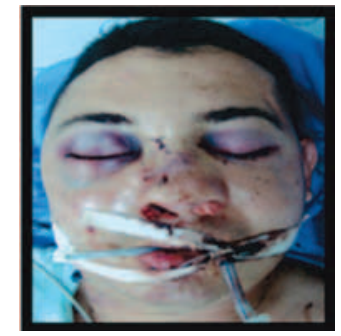

A

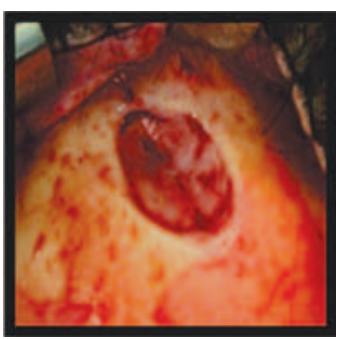

E

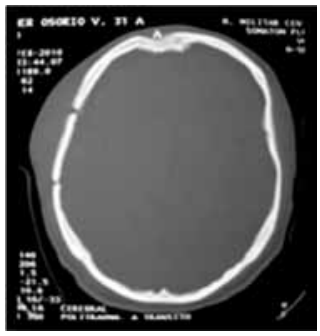

B

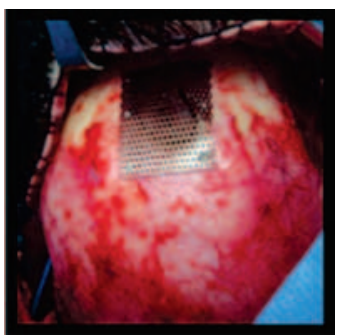

$\mathbf{F}$

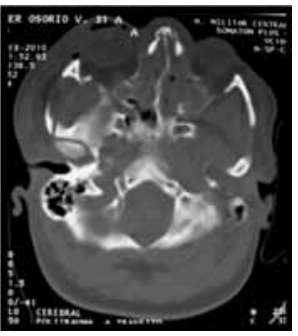

C

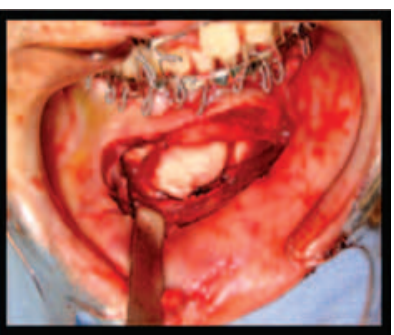

G

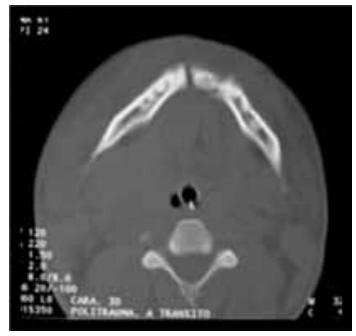

D

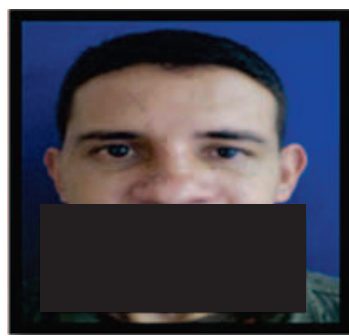

I

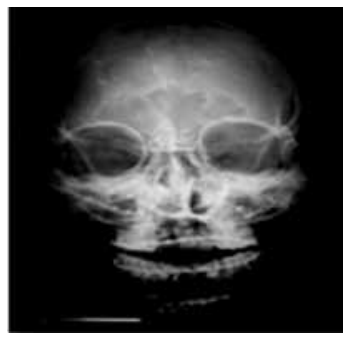

J

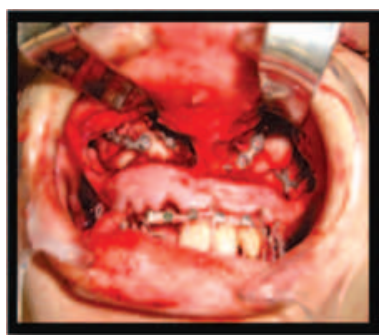

H

Figura 14. Paciente con fracturas por accidente de tránsito

\section{Caso 4}

Paciente de 23 años remitido del Vichada con 15 horas de evolución posterior a trauma cráneo-facial y torácico severo por onda explosiva de tubo a gas a corta distancia. Ingresa al HMC con Glasgow de 4/15, equimosis periorbital bilateral, hemorragia subconjuntival bilateral, pupilas mióticas isocóricas, telecanto traumático, pérdida de continuidad ósea en pilares cigomático-maxilar, rinoliquia, pérdida de continuidad ósea en reborde infraorbitario izquierdo, movilidad de tercio medio facial, retrusión maxilar, intraoral, pérdida de los dientes del sector anterosuperior, herida en vestíbulo superior con secreción purulenta, pérdida de continuidad ósea en sínfisis mentoniana con movilidad de fragmentos y movilidad dental (figuras $15 \mathrm{~A}$ y B). En las figuras 15C, D y E se muestran tomografías donde se observa hematoma epidural, fractura base de cráneo y de hueso temporal, fractura frontal de pared anterior desplazada, fractura Lefort III, fractura sagital maxilar, fractura sínfisis, trauma dentoalveolar antero superior $e$ inferior. El paciente ingresa a la UCI y al tercer día de su ingreso y en colaboración con el servicio de neurocirugía, se realiza procedimiento quirúrgico con abordaje coronal, drenaje hematoma epidural, cierre fístula de LCR, verificación de drenaje del seno frontal y reducción fractura frontal de pared anterior con sistema 1,0 y reducción de fracturas faciales (figuras $15 \mathrm{~F} \mathrm{y} \mathrm{G}$ ). En las figuras $15 \mathrm{H}$, I y J se muestra una fotografía e imágenes de control a los diez días de evolución. En la figuras 15K, Ly M se muestra la tomografía y fotos del paciente el día del control a los 18 meses del trauma. 


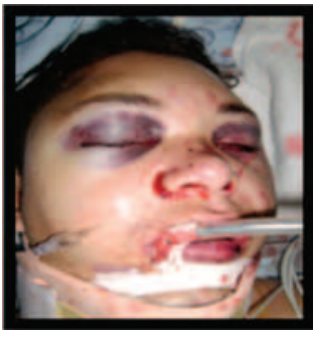

A

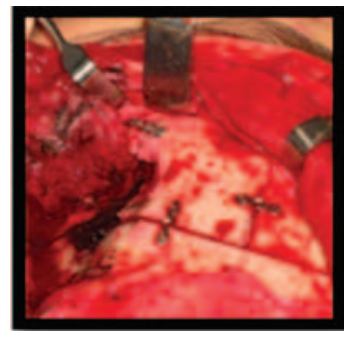

$\mathbf{F}$

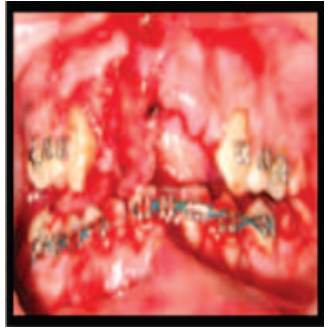

B

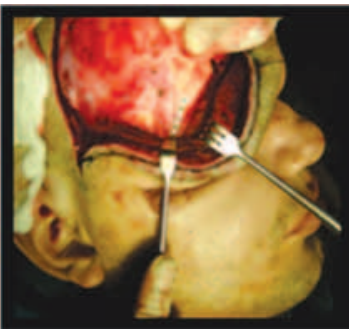

G

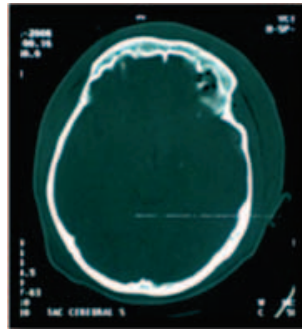

C

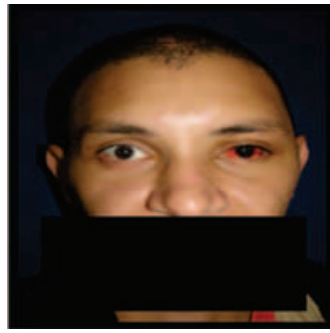

H

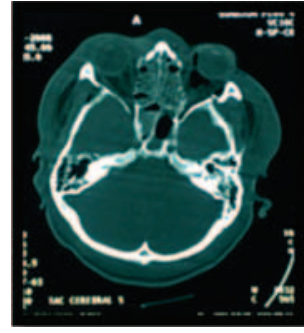

D

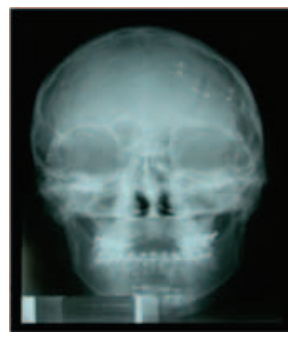

I

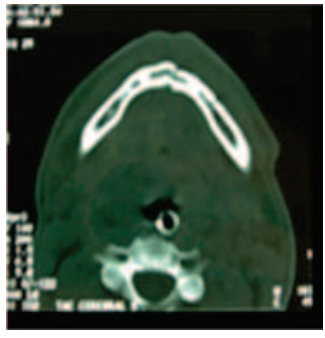

E

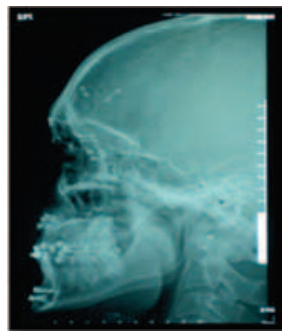

J

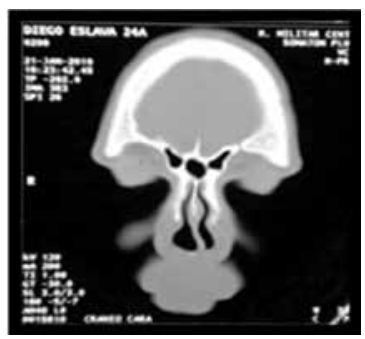

$\mathbf{K}$

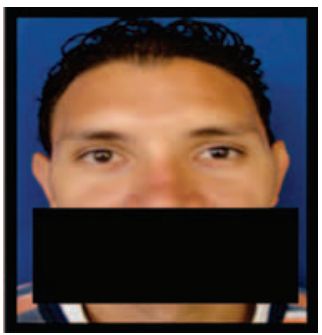

$\mathbf{L}$

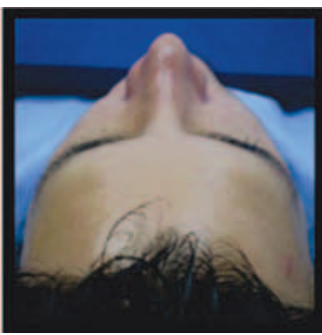

M

Figura 15. Paciente con trauma cráneo-facial y torácico severo por onda explosiva de tubo a gas a corta distancia.

\section{Caso 5}

Paciente de 21 años de edad remitida de Apartadó, Antioquia, con un cuadro de evolución de 48 horas por herida de arma de fragmentación en acto terrorista. $\mathrm{Al}$ ingreso se observa heridas con avulsión de tejidos blandos en región palpebral superior e inferior de ojo derecho y estallido de ambos globos oculares. Ingresa a la UCI del HMC con diagnóstico de POP de cesárea de urgencias por encontrarse en la semana 38 de gestación, shock hipovolémico con permanencia en la UCI por 30 días (figura 16A). El diagnóstico fue trauma ocular abierto bilateral, OD evisceración traumática, fractura frontal conminuta de pared anterior y fractu- ra NOE bilateral tipo III (figuras $16 \mathrm{~B}$ y C). Se realiza procedimiento quirúrgico a los 22 días de su ingreso, con manejo de diferentes especialidades, abordaje por sus heridas a nivel frontal, se realizo evisceración OD, colocación de implante, reconstrucción de parpados, corneoesclerorrafía, verificación del drenaje del receso frontal, retiro de mucosa sinusal en los fragmentos óseos, se mantiene el seno funcional y se reubican los fragmentos de la pared anterior frontal con sistema 1.0, reducción fractura NOE III con sistema 1.0, cantopexia bilateral y rotación de colgajo frontal (figuras 16D, E, F y G). Se hicieron controles posoperatorios periódicos a la paciente (figuras $16 \mathrm{H} \mathrm{e} \mathrm{I}$ ). En la figura $16 \mathrm{~J}$ se muestra una imagen de control a los dos meses. 


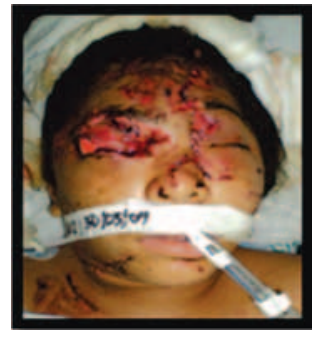

A

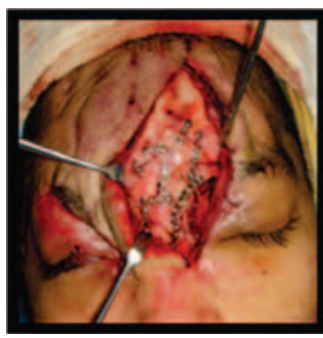

$\mathbf{F}$

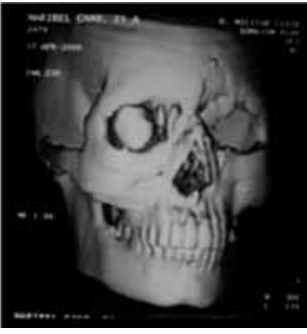

B

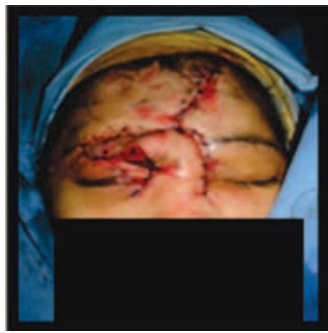

G

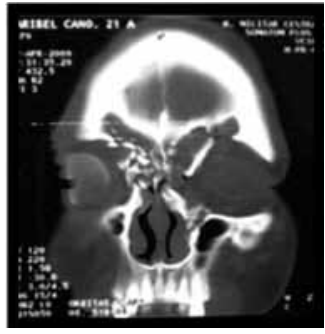

C

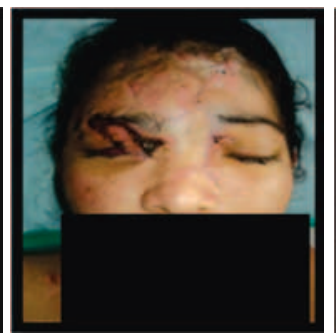

H

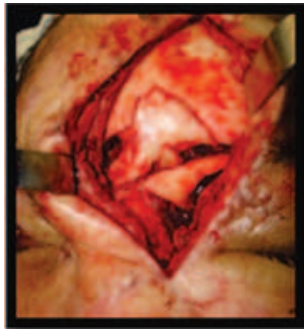

D

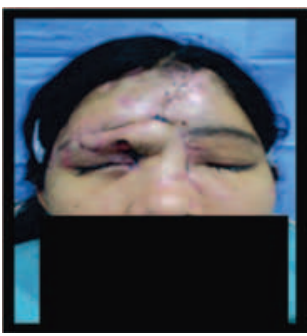

I

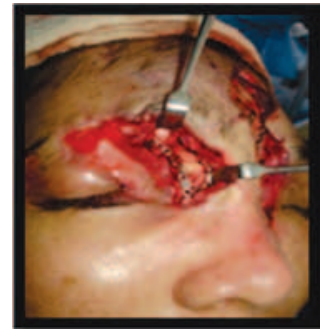

E

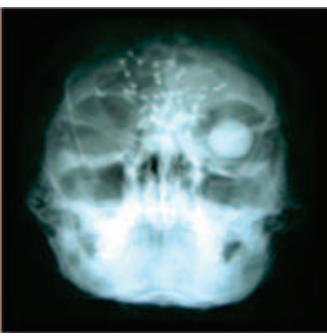

$\mathbf{J}$

Figura 16. Paciente con herida de arma de fragmentación en acto terrorista.

\section{Caso 6}

Paciente de 21 años con trauma facial por herida de arma de fragmentación en combate, manejado inicialmente en otra institución hospitalaria donde le realizaron lavado y desbridamiento de heridas, colocación de malla osteosíntesis en zona frontal y piso craneal anterior, corrección de fístula craneoetmoidal, injerto de neuropach y rotación de colgajo nasal. En la figura 17A se muestra la foto tomada el día de ingreso al HMC, un mes y quince días después del trauma con dacrioestenosis izquierda. OD: Ptosis, enoftalmo, fístula activa purulenta cantal medial, agudeza visual de OD: 20/200 y OI: 20/800, midriasis no reactiva. En las figuras $17 \mathrm{~B}$ y $\mathrm{C}$ se muestran las tomografías en donde se observa fractura avulsiva de pared anterior y posterior de seno frontal, con una malla de titanio que invade zona de orbita fractura NOE III bilateral y fractura seno maxilar izquierdo. A los diez días de su ingreso se realiza procedimiento quirúrgico con abordaje coronal, se retira el material de osteosíntesis, drenaje de hematoma epidural, desfuncionalización y cranealización, obliteración con colgajo pericraneal y fijación interna rígida de craneotomía anterior (figuras 17D, Ey F). La figura $17 \mathrm{G}$ es una tomografía de control en donde se observa el material de osteosíntesis en la pared anterior del hueso frontal. En la figura $17 \mathrm{H}$ se muestra una fotografía en el postoperatorio tardío, se observa contractura cicatrizal en región frontal y facialmente palpable el material de osteosíntesis. Se coloca expansor tisular por el servicio de cirugía plástica del Hospital Militar (figura 17I). El servicio de cirugía maxilofacial planifica y coloca un implante especifico para paciente (PSI) (figura 17J). A los 9 meses el servicio de otorrinolaringología realiza dacriocistorinostomía izquierda (figura 17K). Ly M: Se realiza controles periódicos al paciente, en las figuras $17 \mathrm{~K}$ y L se muestran las imágenes de control a los cinco meses donde se observa restablecimiento de la función del paciente con una estética considerablemente aceptable de acuerdo a sus condiciones iniciales. 


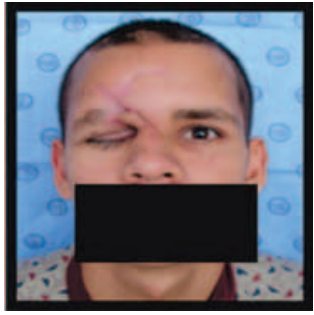

A

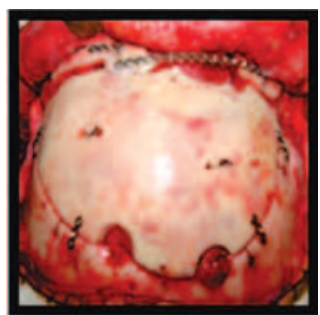

$\mathbf{F}$

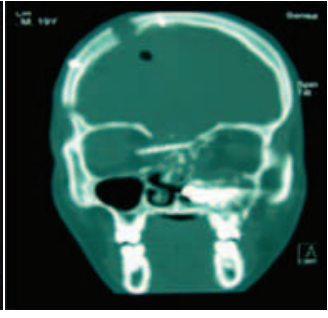

B

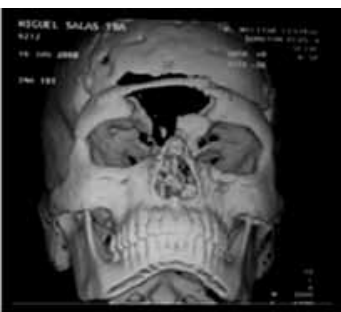

G

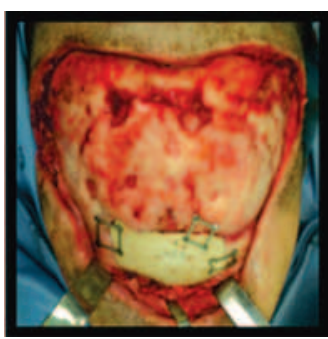

K

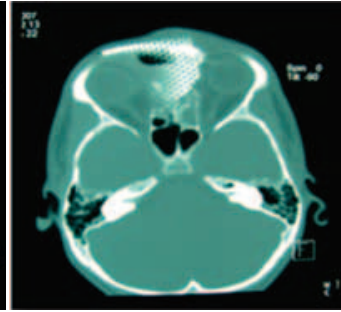

C

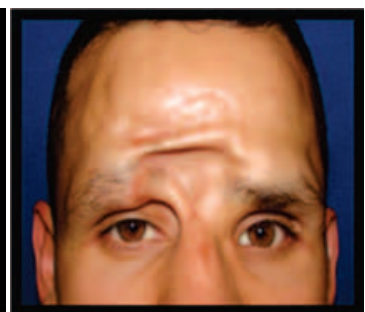

H

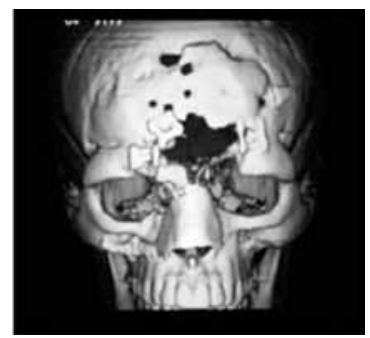

$\mathbf{L}$

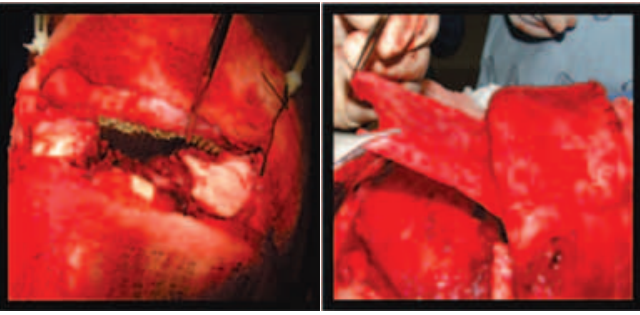

D

$\mathbf{E}$

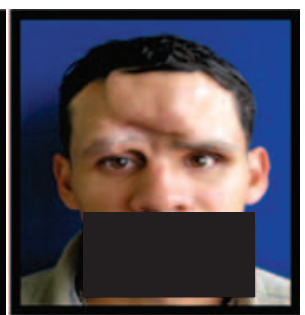

I

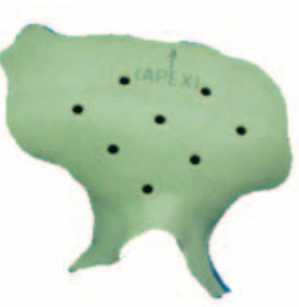

J

Figura 17. Paciente de 21 años con trauma facial por herida de arma de fragmentación en combate.

\section{Caso 7}

Paciente de 26 años con trauma facial por accidente de tránsito, remitido al $\mathrm{HMC}$ con un cuadro de evolución de quince horas (figuras 18A, B y C) en donde es ingresado a la UCI. En las figuras 18D,E, F y G se muestran las tomografías donde se observa fractura frontal con fractura conminuta de pared anterior de seno frontal, fractura reborde orbitario superior bilateral, fractura Lefort tipo III, fractura en parasínfisis mandibular entre 42 y 43 y fractura dentoalveolar. A los dos días de su ingreso se le realizó procedimiento quirúrgico con traqueotomía y gastrostomía, fijación intermaxilar, reducción de fractura mandibular con sistema 2.0 mandibular; abordaje bicoronal exposición de focos de fractura, verificación de estado del receso frontal, desfuncionalizacion del seno frontal y obliteración del receso y seno frontal con grasa autologa de abdomen, reducción de fractura conminuta de pared anterior de seno con sistema 1.0, reducción y fijación de facturas de pilares frontomalares con sistema 1.5, abordajes subciliares e intraorales y exposición de fracturas de tercio medio, reducción y fijación de fracturas con sistema 2.0 maxilar y reborde infraorbitarios con sistema 1.5 , cantoplastia y alambrado transnasal (figuras $18 \mathrm{H}$, I, J, K y L). Se procede a un segundo tiempo quirúrgico con el servicio de oculoplastia, para correcion de defecto de atrapamiento de pared orbital izquierda con reducción de fractura, colocación de malla en pared de orbita lateral izquierda y cantoplastia (figura 18M). En las figura $18 \mathrm{~N}$ y O se muestran las imágenes tomadas como control del procedimiento. En la figura 18P se muestra foto de control tomada a las dos semanas de los procedimientos quirúrgicos. 


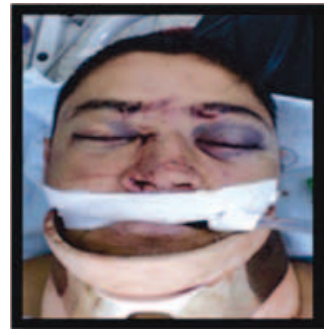

A

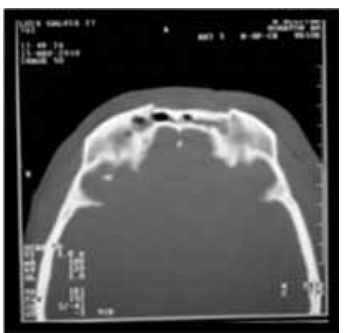

E

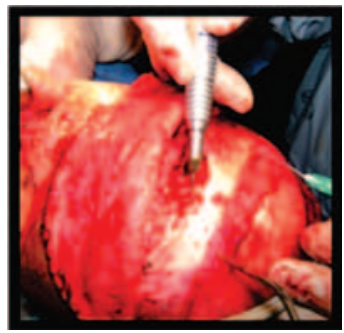

I

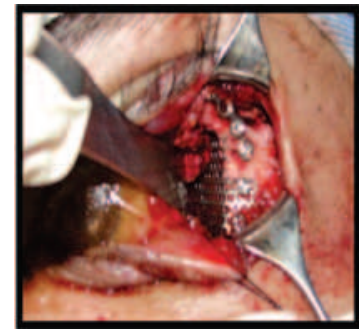

$\mathbf{M}$

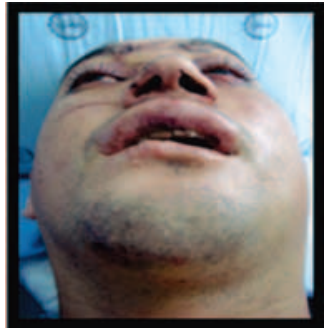

B

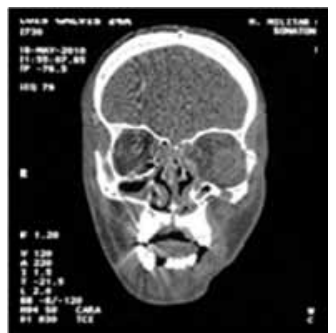

$\mathbf{F}$

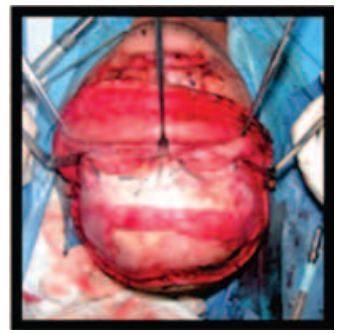

J

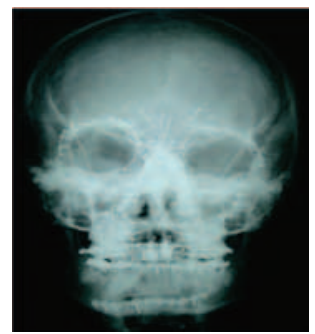

$\mathbf{N}$

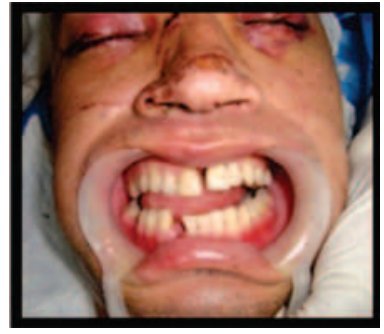

C

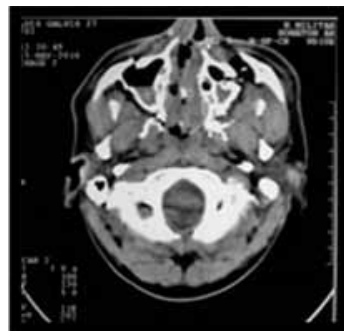

$\mathbf{G}$

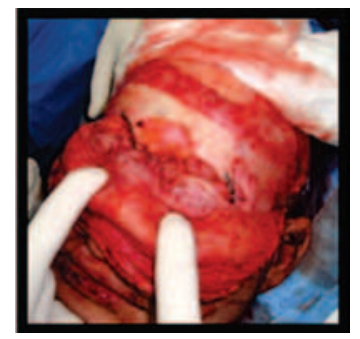

$\mathbf{K}$

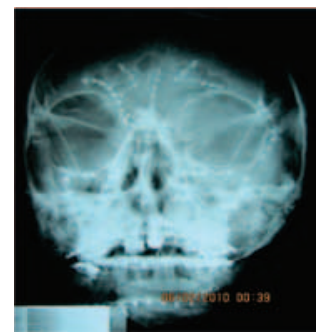

$\mathbf{O}$

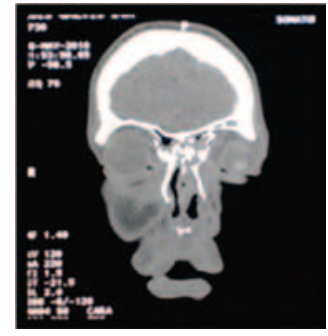

D

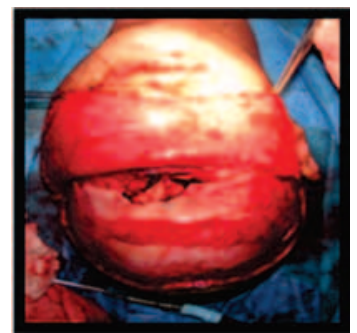

H

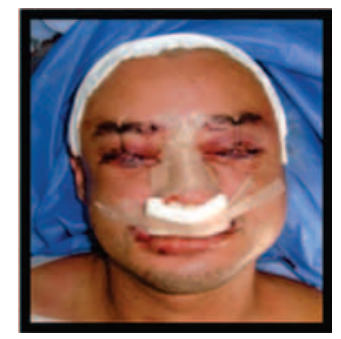

$\mathbf{L}$

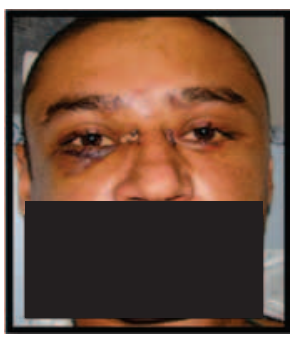

$\mathbf{P}$

Figura 18. Paciente con trauma facial por accidente de tránsito

\section{Conclusiones}

El manejo actual del seno frontal se basa en la anatomía y principios fisiológicos de función y drenaje del receso frontonasal; el plan de tratamiento debe ser enmarcado en los principios de manejo frontal y reducción de fracturas. Al realizar la evaluación intraoperatoria, el cirujano debe tener la capacidad de escoger el procedimiento más adecuado en el momento de la cirugía, con el principal objetivo de proteger las estructuras craneales y contaminación de la vía respiratoria. 


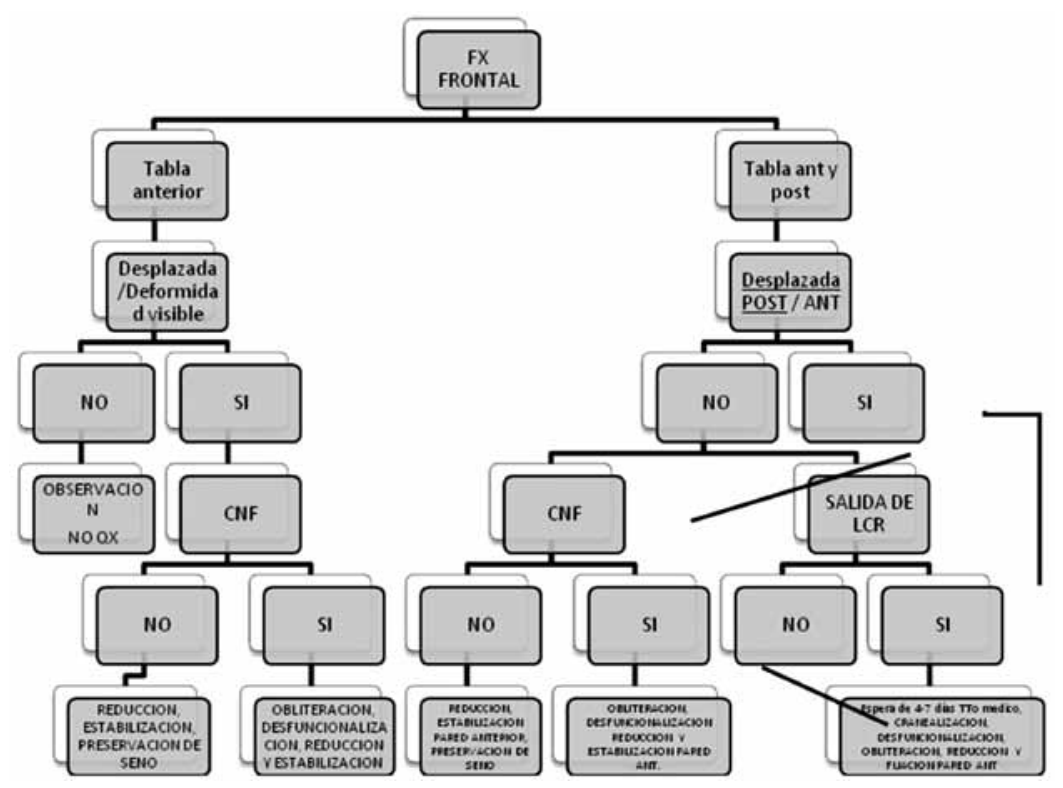

Figura 19. Algoritmo del Hospital Militar Central elaborado por el GITF: Grupo integrado de trauma facial: Servicios de Cirugía Maxilofacial, Otorrinolaringología, Cirugía Plástica.

El Grupo integrado de trauma facial conformado por los servicios de Cirugía oral y maxilofacial, Cirugía plástica y ORL, con el apoyo de Neurocirugía y Oculoplastia del HMC de Bogotá, Colombia, estandarizó los protocolos de manejo para los casos de trauma frontal, los cuales se actualizan anualmente. La guía de manejo para el tratamiento depende de cada caso y se muestra en la figura 19.

Es importante realizar un buen examen físico y contar con ayudas diagnósticas que permitan orientar al clínico en la clasificación del trauma, a determinar que estructuras están comprometidas, a planificar el tratamiento con todos los principios quirúrgicos evitando al máximo complicaciones posteriores. Es necesario hacer un plan terapéutico en la evaluación inicial y controles periódicos cada seis meses inicialmente y luego cada año, con el fin de controlar y prevenir complicaciones tardías las cuales pueden ser devastadoras y que pueden aparecer muchos años después del tratamiento. El manejo de este tipo de trauma es multidisciplinario, en donde participan profesionales entrenados quienes están capacitados para diseñar el tratamiento adecuado en cada caso.

\section{Agradecimientos}

Al grupo integrado de trauma del HMC que ha participado en el manejo integral de los pacientes presentados en el articulo, y que está conformado por el equipo de trabajo del Servicio de Cirugía Oral y Maxilofacial, al Dr Luis Alberto Ruiz del Servicio de Oculoplastia, a los Drs. Ricardo Silva y Maria D. Cardozo del Servicio de Otorrinolaringologia y a los Drs. Mauricio Sabogal y Luis Eduardo Nieto R. del Servicio de Cirugía Plástica.

\section{Referencias}

1. Pankaj T, Higuera S, Thornton J and Hollier L. H. The Management of Frontal Sinus Fractures. J Oral Maxillofac Surg. 2005;63:1354-1360

2. El khatib K, Danino A and Malka G. The Frontal Sinus: a culprit or a victim, A review of 40 cases. Journal of Cranio-maxillofacial Surgery. 2004; 32: 314-317

3. Manolidis S. Frontal Sinus Injuries: Associated Injuries and Surgical Management of 93 Patients. J Oral Maxillofac Surg. 2004; 62:882-891.

4. Fraioli R, Branstetter B, Deleyiannis F. Facial Fractures: Beyond Le Fort. Otolaryngol Clin N Am. 2008;41:51-76

5. Rontal M. State of the Art in Craniomaxillofacial Trauma: Frontal Sinus. Current Opinion in Otolaryngology \& Head and Neck Surgery. 2008;16:381-86.

6. Luce E. Frontal Sinus Fractures: Guidelines to Management. Plastic and reconstructive surgery. 1985;8(4):500-09.

7. Latarjet M, Ruiz Liard A. Anatomía Humana. 1997. 3 edición. 1:1203-1204.

8. Rice D H. Management of Frontal Sinus Fractures. Current Opinion in Otolaryngology \& Head and Neck Surgery. 2004; 12:46-48.

9. Fonseca, Walker, Betts, Barber, Powers, R. Oral and Maxillofacial trauma, 2005; 3 edición, Vol 2. 23:726.

10. Smith T, Han J, Loehrl T and Rhee J. Endoscopic Management of the Frontal Recess in Frontal Sinus Fractures: A Shift in the Paradigm?. Laryngoscope. 2002;112:784-790. 
11. Poetker D. and Smith T. Endoscopic Treatment of the Frontal Sinus Outflow Tract in Frontal Sinus Trauma. Operative Techniques in Otolaryngology. 2006;17:66-72.

12. Kountakis S, Senior B. The Frontal Sinus. 2005. 1 Edición. Cap 2, 3, 16, 20

13. Manolidis S, Hollie L H. Management of frontal sinus fractures. Plast. Reconstr. 2007;120:32-48.

14. Bell R B. Management of Frontal Sinus Fractures. Oral Maxillofacial Surg Clin N Am. 2009;21:227-242.

15. Gonty A. Marciani R, Adornato D. Management of Frontal Sinus Fractures: A Review of 33 Cases. J Oral Maxiiiofac Surg. 1999;57:372-379.

16. Rodriguez, Tovar. Clasificación de Fracturas Faciales. Revista Colombiana de Cirugía Oral y Maxilofacial. 2010;2(2):40-50.

17. Ellis E, Scott K. Assessment of Patients with Facial Fractures. Emergency Medicine Clinics of North America. 2000;18(3):41148.

18. Chen K, Chen T, Mardini S, Tsay P, Chen Y. Frontal Sinus Fractures: A Treatment Algorithm and Assessment of Outcomes Based on 78 Clinical Cases. Plastic and Reconstructive Surgery. 2006;118(2):457-68.

19. Bell R B, Dierks E, Pardeep B, Potter J, Potter B. A Protocol for the Management of Frontal Sinus Fractures Emphasizing Sinus Preservation. J Oral Maxillofac Surg. 2007;65:825-39.

20. Real M, Cabrini M, Hochuli-Vieira, Pereira-Fillho V. Immediate Reconstruction of Frontal Sinus Fractures: Review of 26 Cases. J Oral Maxillofac Surg. 2004;62:582-86.

21. Yoo K, Song H, Lee B, Jang J. Endoscopic Transnasal Reduction of an Anterior Table Frontal Sinus Fracture: Technical Note. $J$ Oral Maxillofac Surg. 2008;37:573-75.

22. Yavuzer R, Sari A, Kelly C, Tuncer S, Latifoglu O, Celeb C, et al. Management of Frontal Sinus Fractures. Plastic and Reconstructive Surgery. 2005;115(6):79-93

23. Rodriguez M, Manson P. Twenty-Six-Year Experience Treating Frontal Sinus Fractures: A Novel Algorithm Based on Anatomical Fracture Pattern and Failure of Conventional Techniques. Plastic and Reconstructive Surgery. 2008;12(6):1850-66.

24. Kalavrezos N. Current Trends in the Management of Frontal Sinus Fractures Injury. Int $J$ Care. 2004;35:340-46.

25. Donath A, Sindwani R. Frontal Sinus Cranialization Using thePericranial Flap: An Added Layer of Protection. Laryngoscope. 2006;116:1585-88.

26. Leipziger L, Bradley S. Acute Management of Frontal Sinus Fractures. Operative Techniques In Plastic and Reconstructive Surgery.1998;5(3):257-265.

27. Lin D, Witterick I. Frontal Sinus Stents: How Long Can They Be Kept In? Journal of Otolaryngohgy-Head \& Neck Surgery. 2008;37(1):119-23.

28. McRae M, Momeni R, Narayan D. Frontal Sinus Fractures: A Review of Trends, Diagnosis, Treatment and Outcomes at a Level 1 Trauma Center in Connecticut. Connecticut Medicine. 2008;72(3):133-38.

29. Loannides C, Freihofer H. Fractures of the Frontal Sinus: Classification and its Implications for Surgical Treatment. American Journal of Otolaryngology. 1999;20(5):273-80.

30. Elahi M, Vanduzer S, Julia A, Jeffrey G, Amithabha M. Frontal Sinus Obliteration With Tricalcium Phosphate. The Journal of Craniofacial Surgery. 2004;15(6):967-70.

31. Tirbod F, Johnson C, Steinberg B. Comparison of 2 Preferred Methods Used for Frontal Sinus Obliteration. J Oral Maxillofac Surg. 2005;63:487-91.
32. Satoyuki I, Nagayama K, Lino N, Saito I and Takami Y. Frontal Sinus Repair with Free Autologous Bone Grafts and Fibrin glue. Surg neurol. 2003;60:155-58.

33. Siddique S, Mathog R. A Comparison of Parietal and Iliac Crest Bone Grafts for Orbital Reconstruction. J Oral Maxillofac Surg. 2002;60:44-50.

34. Fattahi T, DiPasquale J. Utility of the Pericranial Flap in Frontal Sinus and Anterior Cranial Fossa Trauma. J Oral Maxillofac. Surg. 2009; 38:1263-67.

35. Kalavrezos N, Gratz K, Warnke T and Sailer H. Frontal Sinus Fractures: Computed Tomography Evaluation of Sinus Obliteration with Lyophilized Cartilage. Journal of Cranio-Maxillofaeial Surgery. 1999;27:20-24.

36. Shumrick K. Endoscopic Management of Frontal Sinus Fractures. Otolaryngol Clin N Am. 2007;40:329-336.

37. Peltola M, Aitasalo K, Suonpa J, Varpula M, Yli-urpo A. Bioactive Glass s53p4 in Frontal Sinus Obliteration: A Long-term Clinical Experience. Head Neck. 2006;28:834-41.

38. Strong B. Frontal Sinus Fractures. Operative Techniques in Otolaryngology. 2008;19:151-60.

39. Gossman D, Archer S, Arosarena O. Management of Frontal Sinus Fractures: A Review of 96 Cases. Laryngoscope. 2006;116:1357-62.

40. Mensink G, Zweers A, Merkesteyn V. Endoscopically Assisted Reduction of Anterior Table Frontal Sinus Fractures. Journal of Cranio-Maxillofacial Surgery. 2008;37:225-28.

41. Smith T, Loehrl T, Rhee J. Treatment Algorithm For Endoscopic Management Of The Frontal Recess In Frontal Sinus Fractures. Operative Techniques In Otolaryngology-Head And Neck Surgery. 2002;13(4):281-86.

42. Chen D, Chen C, Chen Y, Feng G. Endoscopically Assisted Repair of Frontal Sinus Fracture. J Trauma. 2003;55:378-82.

43. Carboni, Perugini, Ramieri, Taglia and Iannetti G. Frontal Sinus Fractures: A Review of 132 Cases. European Review for Medical and Pharmacological Sciences. 2009;13:57-61.

44. Tedaldi M, Ramieri V, Foresta E, Cascone P and Iannetti G. Experience in the Management of Frontal Sinus Fractures. $J$ Craniofac Surg. 2010;21(1):208-10.

45. Stanley R. Management of Complications of Frontal Sinus and Frontal Bone Fractures. Operative Techniques in Plastic and Reconstructive Surgery. 1998;5(4):296-301.

46. Collet S, Grulois V, Boy P, Rombaux B, Bertrand B. A Potts Puffy Tumour as a Late complication of a Frontal Sinus Reconstruction: Case Report and Literature Review. Rhinology. 2009;47:470-75.

47. Hwang K, Young E. Delayed Development of Mucocele in the Fractured Frontal Sinus. The Journal of Craniofacial Surgery. 2008;19(5):1419-22.

48. Galie M, Mandrioli S, Tieghi R, Clauser L. Giant Mucocele of the Frontal Sinus. The Journal of Craniofacial Surgery. 2005;16(5):933-35.

49. Wynn R, Vaughan W. Treatment of Failed Frontal Sinus Obliteration. Operative Techniques in Otolaryngology. 2006;17:13-18.

50. Cultrera F, Giuffrida M, Mancuso P. Delayed Post-traumatic Frontal Sinus Mucopyocoele Presenting with Meningitis. Journal of Cranio-Maxillofacial Surgery. 2006; 34: 502-504

51. Suri A, Mahapatra A, Gaikwad S, Sarkar C. Giant Mucoceles of the Frontal Sinus: A Series and Review. Journal of Clinical Neuroscience. 2004;11(2):214-18.

52. Koudstaal M, Van Der Wal K, Bijvoet H, Vincent A, Poublon R. Post-trauma Mucocele Formation in the Frontal Sinus; A Rationale of Follow-up. J Oral Maxillofac Surg. 2004;33:751-54. 